OPEN ACCESS

Edited by:

Selena Ahmed,

Montana State University,

United States

Reviewed by:

Martina Bednárová,

Mendel University in Brno, Czechia

Marie Borkovcova,

Mendel University in Brno, Czechia

*Correspondence:

Mauro Serafin

mserafini@unite.it

Specialty section:

This article was submitted to

Nutrition and Sustainable Diets,

a section of the journal

Frontiers in Nutrition

Received: 15 March 2019

Accepted: 27 June 2019

Published: 15 July 2019

Citation:

Di Mattia C, Battista N, Sacchetti G and Serafini M (2019) Antioxidant

Activities in vitro of Water and

Liposoluble Extracts Obtained by

Different Species of Edible Insects and

Invertebrates. Front. Nutr. 6:106.

doi: 10.3389/fnut.2019.00106

\section{Antioxidant Activities in vitro of Water and Liposoluble Extracts Obtained by Different Species of Edible Insects and Invertebrates}

\author{
Carla Di Mattia, Natalia Battista, Giampiero Sacchetti and Mauro Serafini* \\ Faculty of Biosciences and Technologies for Agriculture, Food, and Environment, University of Teramo, Teramo, Italy
}

A new global interest in entomophagy, the practice of eating insects, and invertebrates, arise from the impellent necessity of preserving agriculture resources and to obtain a drastic reduction of the ecological impact of animal food on the planet. The composite nutritional content, direct consequences of a plant-based feeding, associated with the undoubtedly ecological properties, suggest for insects a role as sustainable and functional foods. We aim to investigate the ability of water and liposoluble extracts, obtained by 12 commercially available edible insects and two invertebrates, to display an antioxidant effect in vitro. Results show that water-soluble extracts of grasshoppers, silkworm, and crickets display the highest values of antioxidant capacity (TEAC), 5-fold higher than fresh orange juice, while evening cicada, giant water bugs, Thai zebra tarantula, and black scorpions have negligible values. Grasshoppers, African caterpillars, and crickets have the highest levels of reducing power (FRAP), double than fresh orange juice. Grasshoppers, black ants, and mealworms contain the highest levels of total polyphenols, while Thai zebra tarantula, black scorpions, and giant water bugs are positioned at the bottom of the ranking. The liposoluble fraction of silkworm, evening cicada, and African caterpillars shows highest level of TEAC, twice than olive oil, while Thai zebra tarantula, palm worm, and black ants are placed at the bottom of the ranking. Edible insects and invertebrates represent a potential source of antioxidant ingredients with an efficiency related to their taxonomy and eating habits. More evidences are needed in order to understand if the practice of eating insects and invertebrates might contribute to modulate oxidative stress in humans.

Keywords: entomophagy, edible insects, edible invertebrates, non-enzymatic antioxidant capacity, novel foods, dietary habits, sustainable nutrition

\section{INTRODUCTION}

Entomophagy, the practice of eating insects and invertebrates, has accompanied the human history through the centuries, playing a significant role in cultural and religious practices (1-3). According to the Food and Agriculture Organization of the United Nations (FAO), insects are part of the common diet of at least two billion people in the world (4). Among the different species available 
for human consumption, Coleoptera (beetles), Lepidoptera (African caterpillars), and Hymenoptera (bees, wasps and ants) represent 31,18 , and $14 \%$ of total insect consumption (4). However, in most western countries, the habit of eating insects is often considered a primitive practice inducing disgust on the basis of insect morphologies.

Recently, a new global interest in edible insects and invertebrates arise from the impellent necessity of preserving agriculture resources to feed the nine billion world's population predicted for 2050 and to obtain a drastic reduction of the ecological impact of meat and derivatives on the planet $(5,6)$. In this view, livestock production is responsible of about $14.5 \%$ of total human-induced greenhouse gas emissions (GHG) (7), one of the main factors inducing climate changes. Under an ecological point of view, insects represent a highly sustainable replacement of meat and animal products, they produce enormously less amount of GHG and require less water, land, and feed to develop their life cycle, compared to livestock (4). Moreover, under a nutritional point of view, insects and invertebrates represent a good source of bioavailable high-quality proteins and essential amino acids, polyunsaturated fatty acids, minerals such as iron, zinc, and potassium, B vitamins, and insoluble fiber, as chitin (4).

As overall, their composite nutritional quality, direct consequences of a plant-based feeding, associated with the undoubtedly ecological properties, suggest for insects a conceivable role as sustainable and functional foods. However, despite insects have been used in traditional medicine in wound healing and as curative therapy for respiratory disorders and stomachache $(8,9)$, there is scarce evidences about functional properties of insects and invertebrates in the literature. Recently, 2 weeks of consumption of a breakfast enriched with $25 \mathrm{~g}$ of cricket powder, was shown to reduce circulating levels of the pro-inflammatory cytokine TNF- $\alpha$ in plasma of 20 healthy adults (10). Moreover, hydrolysates from Tenebrio molitor larvae displayed free radical scavenging activity $(11,12)$ and peptides fraction from the locust Schistocerca Gregaria exhibit inhibitory activity of lipoxygenase and cyclooxygenase 2 (12). In myoblast cell lines, the cricket Brachytrupes orientalis has been shown to decrease intracellular reactive oxygen species (ROS) production, lipid peroxidation, and up-regulating expression of protein Nrf2 and glutathione S-transferase, involved in the red-ox response to stress, following high glucose stimulation (13). However, no evidence is present in the literature about a screening of the antioxidant properties of insects and invertebrates available for human consumption.

In this work, we aim to investigate and compare the ability of water and liposoluble extracts, obtained by commercially available edible insects and invertebrates, representative of different species and eating habits, to exhibit an antioxidant effect in vitro.

\footnotetext{
Abbreviations: FRAP, ferric reducing antioxidant power; GAE, gallic acid equivalent; ROS, reactive oxygen species; TEAC, Trolox equivalent antioxidant capacity; TPI, total polyphenol index; GHG, greenhouse gas emissions; CVD, cardiovascular disease.
}

\section{MATERIALS AND METHODS}

\section{Sample Preparation}

Edible insects and invertebrates, purchased from Eatgrub (UK) and Insectemente-votre (FR), are described in Table $\mathbf{1}$ according to name, family classification, dietary habits, and energy content. Orange juice was freshly made by oranges purchased in local supermarkets. Olive oil was purchased in local supermarket. The water content of the insects was within the range $2-7 \%$, with the exception of black ants (46\%) and black scorpions (22\%), whilst the water content of orange juice was $88 \%$. Before samples size reduction, wings, and paws in grasshoppers and stingers in scorpions were removed and discharged according to supplier instructions; grinding of the samples was carried out in a lab-scale mixer (Bimby TM31, Vorwerk, Wuppertal, Germany). All the other samples were grounded without any pre-treatment since, as stated in the labels, they were ready to use.

\section{Sample Defatting and Extraction of the Lipo-Soluble Fraction}

Grounded insects ( $4 \mathrm{~g}$ ) were defatted with three cycles of hexane washing $(25 \mathrm{~mL})$. Each time, the mixture was first vortexed ( $1 \mathrm{~min}$ ) and then centrifuged at $2,346 \mathrm{~g}$ in an ALC $4237 \mathrm{R}$ centrifuge (Milan, Italy) for $10 \mathrm{~min}$; at each cycle the surnatant was recovered and the three combined fractions represented the liposoluble extracts. All the extracts were concentrated at $37^{\circ} \mathrm{C}$ under vacuum using a rotative evaporator (Büchi Labortechnik, Flawil, Switzerland). The lipid-free solids were air-dried at room temperature until complete removal of hexane and then used for the extraction of the water-soluble extracts.

\section{Extraction of the Water-Soluble Fraction}

Dried and defatted insects $(1 \mathrm{~g})$ were added to $25 \mathrm{~mL}$ of distilled water and homogenized for $1 \mathrm{~min}$ using a Vortex mixer (IKA, Staufen, Germany). The homogenate was put in a $50 \mathrm{~mL}$ capped vial, wrapped in an aluminum sheet and extracted for $1 \mathrm{~h}$ in a shaker, which was kept at $18^{\circ} \mathrm{C}$ under dark conditions. The homogenate was centrifuged for $15 \mathrm{~min}$ at $2,346 \mathrm{~g}$ in an $4237 \mathrm{R}$ ALC (Milan, Italy) centrifuge set at $4^{\circ} \mathrm{C}$ and the surnatant was filtered through cellulose filters; water was added to a final volume of $25 \mathrm{~mL}$. The extract obtained was then used to quantify the total polyphenols index (TPI) and to determine the antiradical and reducing activity by the ABTS and FRAP methods, respectively.

\section{Radical Scavenging Activity (TEAC)}

The radical scavenging activity was measured by the ABTS $\left[2,2^{\prime}-\right.$ azino-nis (3-ethylbenzthiazoline-6-sulfuric acid)] radical cation decoloration assay, as described by Re et al. (14). The bleaching rate of $\mathrm{ABTS}^{+} \bullet$ in the presence of the sample was monitored at $734 \mathrm{~nm}$ using a Perkin Elmer (Boston, MA, USA) Lambda Bio 20 spectrophotometer. The $\mathrm{ABTS}^{+} \bullet$ stock solution was diluted either in water or ethanol up to an Abs of $0.70 \pm 0.02$ for the analysis of the aqueous and apolar extracts, respectively. Volumes of 2.97 and $2.88 \mu \mathrm{L}$ of $\mathrm{ABTS}^{+} \bullet$ solution were used for hydrophilic and lipophilic extracts, respectively. The reaction was started by the addition of 30 and $120 \mu \mathrm{L}$ of hydrophilic 
TABLE 1 | Classification, dietary habits, and energy values of the selected edible insects and invertebrates.

\begin{tabular}{|c|c|c|c|c|}
\hline Order & Name & Family & Dietary habits & $\begin{array}{l}\text { Energy value } \\
\text { (kcal/100 g) }\end{array}$ \\
\hline \multicolumn{5}{|l|}{ Insects } \\
\hline Coleoptera & $\begin{array}{l}\text { Buffalo worms } \\
\text { (Alphitobius diaperinus) }\end{array}$ & Tenebrionidae & Herbivorous & 484 \\
\hline Hemiptera & $\begin{array}{l}\text { Evening cicada } \\
\text { (Tanna japonensis) }\end{array}$ & Cicadidae & Plant vascular system & n.a. \\
\hline Hymenoptera & $\begin{array}{l}\text { Black ants } \\
\text { (Lasius niger) }\end{array}$ & Formicidae & $\begin{array}{l}\text { Herbivorous and } \\
\text { saprophagous }\end{array}$ & 329 \\
\hline Lepidoptera & $\begin{array}{l}\text { African caterpillars } \\
\text { (Imbrasia oyemensis) }\end{array}$ & & Herbivorous & n.a. \\
\hline Orthoptera & $\begin{array}{l}\text { Crickets } \\
\text { (Acheta domesticus) }\end{array}$ & Gryllidae & Herbivorous & 458 \\
\hline Orthoptera & $\begin{array}{l}\text { Mini crickets } \\
\text { (Acheta domesticus) }\end{array}$ & Gryllidae & Herbivorous & 487 \\
\hline Rhynchota & $\begin{array}{l}\text { Giant water bugs } \\
\text { (Lethocerus indicus) }\end{array}$ & Belostomatidae & Carnivorous & n.a. \\
\hline Scolopendromorpha & $\begin{array}{l}\text { Scolopendra gigantea } \\
\text { (Scolopendra) }\end{array}$ & Scolopendridae & Herbivorous & n.a. \\
\hline \multicolumn{5}{|l|}{ Invertebrates } \\
\hline Arachnida & $\begin{array}{l}\text { Thai zebra tarantula } \\
\text { (Haplopelma albostriatum) }\end{array}$ & Theraphosidae & Carnivorous & 450 \\
\hline Scorpiones & $\begin{array}{l}\text { Black scorpion } \\
\text { (Pandinus imperator) }\end{array}$ & Scorpioniade & Carnivorous & n.a. \\
\hline
\end{tabular}

and lipophilic extracts to aqueous and ethanolic ABTS solution, respectively. The $\mathrm{ABTS}^{+\bullet}$ bleaching was monitored at $30^{\circ} \mathrm{C}$ and the decoloration after $5 \mathrm{~min}$ was used as the measure of antioxidant activity. Radical scavenging activity was measured as Trolox Equivalents Antioxidant Capacity (mmol of Trolox eq. per $100 \mathrm{~g}$ of sample) and calculated by the ratio of the correlation coefficient of the dose-response curve of the sample and the correlation coefficient of the dose-response curve of the standard compound. Trolox was used as standard for the calculation of the radical scavenging activity for both the water soluble $\left(\mathrm{TEAC}_{\mathrm{aq}}\right)$ and liposoluble extracts $\left(\mathrm{TEAC}_{\text {lipo }}\right)$.

\section{Ferric Reducing Antioxidant Power (FRAP)}

The reducing activity of the samples was determined according to the method described by Benzie and Strain (15) with some modifications. One hundred microliters of opportunely diluted sample extract were added to $2,900 \mu \mathrm{L}$ of the FRAP reagent obtained by mixing acetate buffer $(300 \mathrm{mM}, \mathrm{pH}$ 3.6), TPTZ (2,4,6-tripyridyl-s-triazine) $10 \mathrm{mM}$ solubilized in $\mathrm{HCl} 40 \mathrm{mM}$ and $\mathrm{FeCl}_{3} 20 \mathrm{mM}$ in the ratio 10:1:1. The absorbance change was followed at $593 \mathrm{~nm}$ for $6 \mathrm{~min}$. A calibration plot based on $\mathrm{FeSO}_{4} \cdot 7 \mathrm{H}_{2} \mathrm{O}$ was used and results were expressed as mmoles of $\mathrm{Fe}^{2+}$ per 100 grams of defatted weight.

\section{Total Polyphenols Index (TPI)}

The TPI was determined according to a procedure modified from Giacintucci et al. (16). The sample extract $(0.1 \mathrm{~mL})$ was diluted with deionized water to a volume of $5 \mathrm{~mL}$ and then 500 $\mu \mathrm{L}$ of Folin-Ciocalteu reagent was added; after $3 \mathrm{~min}, 1.5 \mathrm{~mL}$ of a $25 \% \mathrm{Na}_{2} \mathrm{CO}_{3}$ solution was added and then deionized water up to $10 \mathrm{~mL}$ final volume. Solutions were maintained at room temperature under dark conditions for $60 \mathrm{~min}$ and the total polyphenols content was determined at $765 \mathrm{~nm}$ using a Perkin Elmer Lambda Bio 20 spectrophotometer. Gallic acid standard (Fluka, Buchs, $\mathrm{CH}$ ) solutions were used for calibration purposes. Results were expressed as milligrams of gallic acid equivalents (GAE) per $100 \mathrm{~g}$ of sample.

\section{RESULTS}

The water-soluble extracts of grasshoppers (2.55 \pm 0.05$)$, silkworm (2.48 \pm 0.19$)$, and crickets $(2.37 \pm 0.03)$ display the highest values of antioxidant capacity, measured as TEAC $_{\mathrm{aq}}$ (mmol TE/100 g), 5-fold higher than fresh orange juice $(0.40 \pm$ 0.01), as described in Figure 1. In the second group of antioxidant activity we found African caterpillars (1.43 \pm 0.11$)$, mealworms $(0.89 \pm 0.09)$, mini crickets $(0.85 \pm 0.09)$, buffalo worms $(0.82$ $\pm 0.07)$, scolopendra $(0.78 \pm 0.04)$, black ants $(0.57 \pm 0.04)$, 


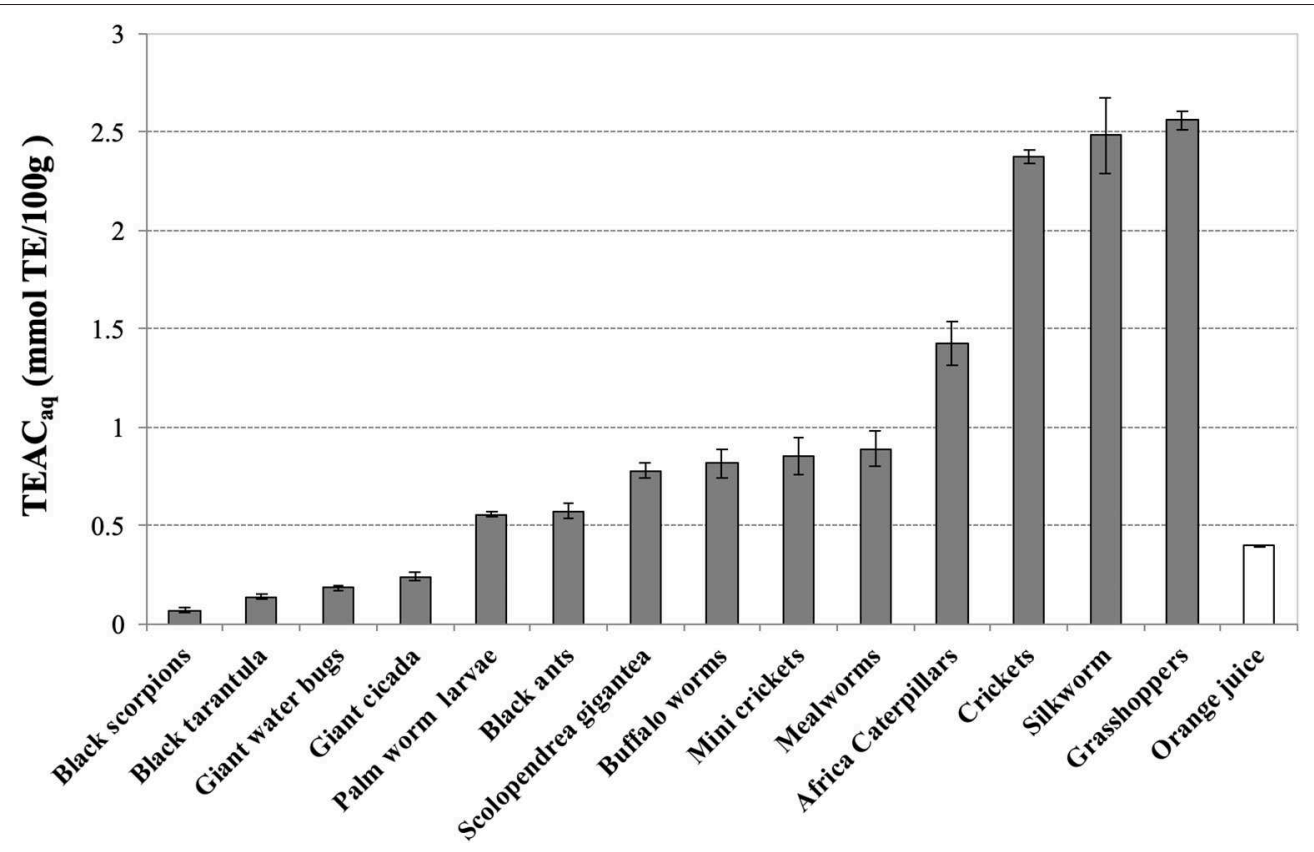

FIGURE 1 | Trolox Equivalent Antioxidant Capacity (TEAC) of water-soluble extracts of edible insects, invertebrates and fresh orange juice. Values are expressed as TEAC $_{a q}$ (mmolTE/100 $\mathrm{g}$ of defatted sample or $100 \mathrm{~mL}$ in the case of orange juice) and are the mean \pm SD in triplicate. TE, Trolox Equivalents.

and palm worm $(0.55 \pm 0.01)$. As overall, majority of extracts, except for evening cicada $(0.24 \pm 0.02)$, giant water bugs $(0.18$ $\pm 0.01)$, Thai zebra tarantula $(0.13 \pm 0.01)$, and black scorpions $(0.06 \pm 0.01)$, have level of antioxidant capacity higher than fresh orange juice.

For what concerns the values of reducing power of water-soluble extracts, grasshoppers (2.12 \pm 0.22$)$, African caterpillars $(1.88 \pm 0.02)$, and cricket $(1.81 \pm 0.06)$ display the highest FRAP values (mmol Fe ${ }^{2+} / 100 \mathrm{~g}$ ), about 2-fold higher than orange juice $(0.94 \pm 0.01)$ (Figure 2$)$. Black ants, mini crickets, mealworms, silkworms, and buffalo worms are in intermediate position with values comparable to orange juice. Thai zebra tarantula $(0.04 \pm 0.00)$ and black scorpions $(0.06 \pm$ $0.00)$ have extremely low values of FRAP.

Grasshoppers (492 \pm 24$)$, black ants (452 \pm 68), and mealworms (406 \pm 12 ) contain the highest levels of TPI (mg GAE/100 g), followed by buffalo worms $(319 \pm 22)$ and crickets $(299 \pm 51)$ (Figure 3). As for the TEAC values, Thai zebra tarantula $(126 \pm 25)$, black scorpions (148 \pm 21$)$, and giant water bugs $(152 \pm 31)$ are positioned at the end of the ranking. Grasshoppers (492 \pm 24$)$ and black ants $(452 \pm 68)$ are the only insects with comparable levels of TPI respect to orange juice (496 \pm 19 ).

When the lipophilic fraction of the extracts was tested, silkworm $(0.136 \pm 0.024)$ and evening cicada $(0.119 \pm 0.010)$ display the highest values of $\mathrm{TEAC}_{\text {lipo }}(\mathrm{mmol} \mathrm{TE} / 100 \mathrm{~g})$, twice than olive oil $(0.063 \pm 0.010)$ (Figure 4). As overall, all the other extracts display similar values, with Thai zebra tarantula $(0.005$ $\pm 0.001)$, palm worm $(0.017 \pm 0.001)$, and black ants $(0.018 \pm$ $0.003)$ at the bottom of the ranking.

\section{DISCUSSION}

Insects and invertebrates are often consumed as whole and, despite some people still view entomophagy as a disgusting practice, it is becoming a popular trend of human nutrition in European countries. It is already well-known that insects and invertebrates represent a valid source of noble proteins, minerals, vitamins, and fatty acids at low ecological impact, however scarce information are available on their role as source of bioactive ingredients. In this work we have shown that commercially available edible insects and invertebrates represent a potential source of antioxidant ingredients, with an efficiency related to their taxonomy and eating habits.

Consumption of foods rich in antioxidants, such as fruit and vegetables, play an important role in the prevention of oxidative stress-related diseases such as cardiovascular disease, diabetes and cancer (17). The in vivo efficiency of antioxidant-rich food is highly dependent from bioavailability and by the presence of an ongoing oxidative stress (18-20). However, a high content of antioxidant in the food matrix it is a primary requisite for a first screening of antioxidant potentiality of novel foods. Since it is always difficult to define if the antioxidant efficiency in vitro is high or low, we have compared the results of some edible insects and invertebrates with the values of antioxidant capacity from fresh orange juice and olive oil, respectively, for the water and lipo-soluble fractions of extracts. Crickets, grasshoppers, silkworm, African caterpillars, and evening cicada display values of antioxidant capacity 2- or 3-fold higher than orange juice or olive oil, functional foods that are known to modulate antioxidant network in humans $(21,22)$. However, despite the promising 


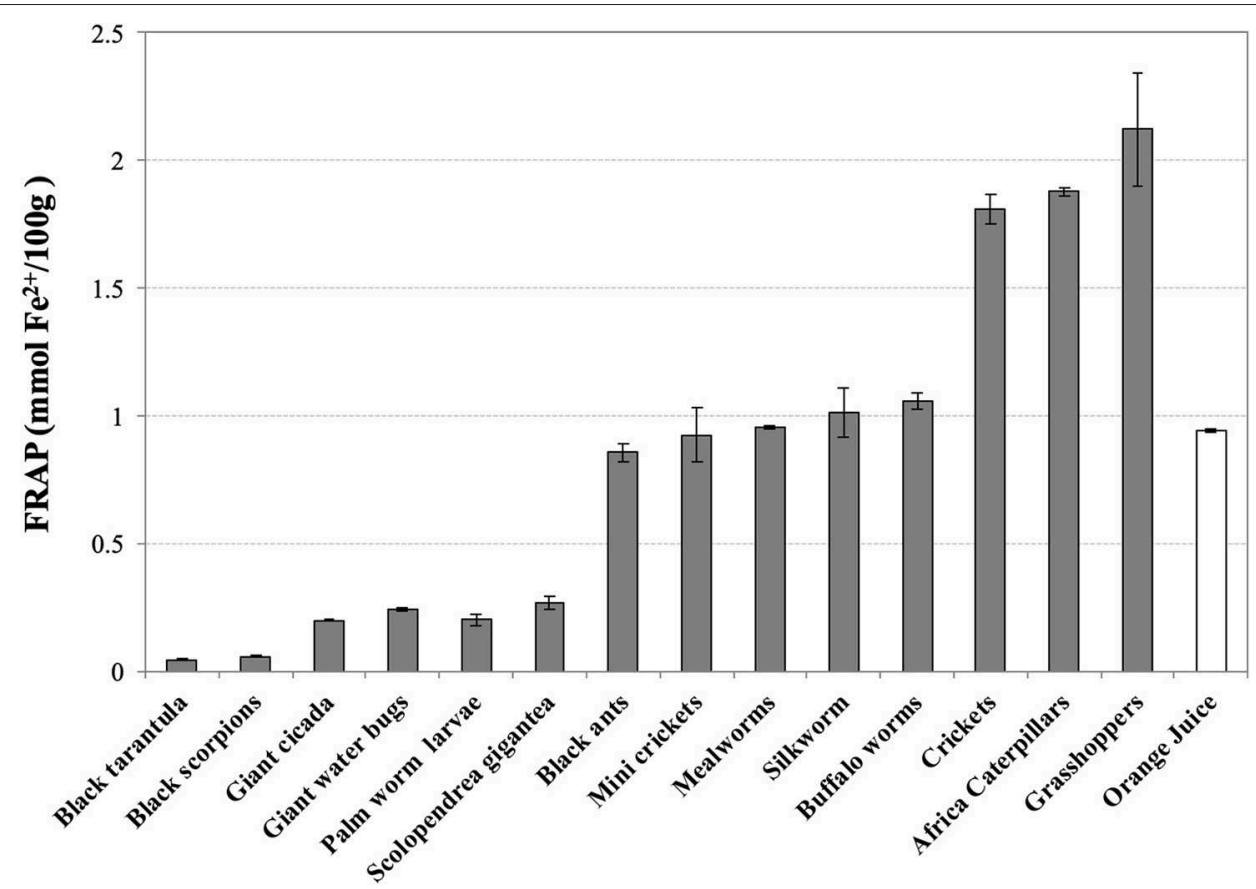

FIGURE 2 | Ferric Reducing Antioxidant Potential (FRAP) of water-soluble extracts of edible insects, invertebrates, and fresh orange juice. Values are expressed as FRAP ( $\mathrm{mmol} \mathrm{Fe} 2+/ 100 \mathrm{~g}$ of defatted sample or $100 \mathrm{~mL}$ in the case of orange juice) and are the mean $\pm \mathrm{SD}$ in triplicate.

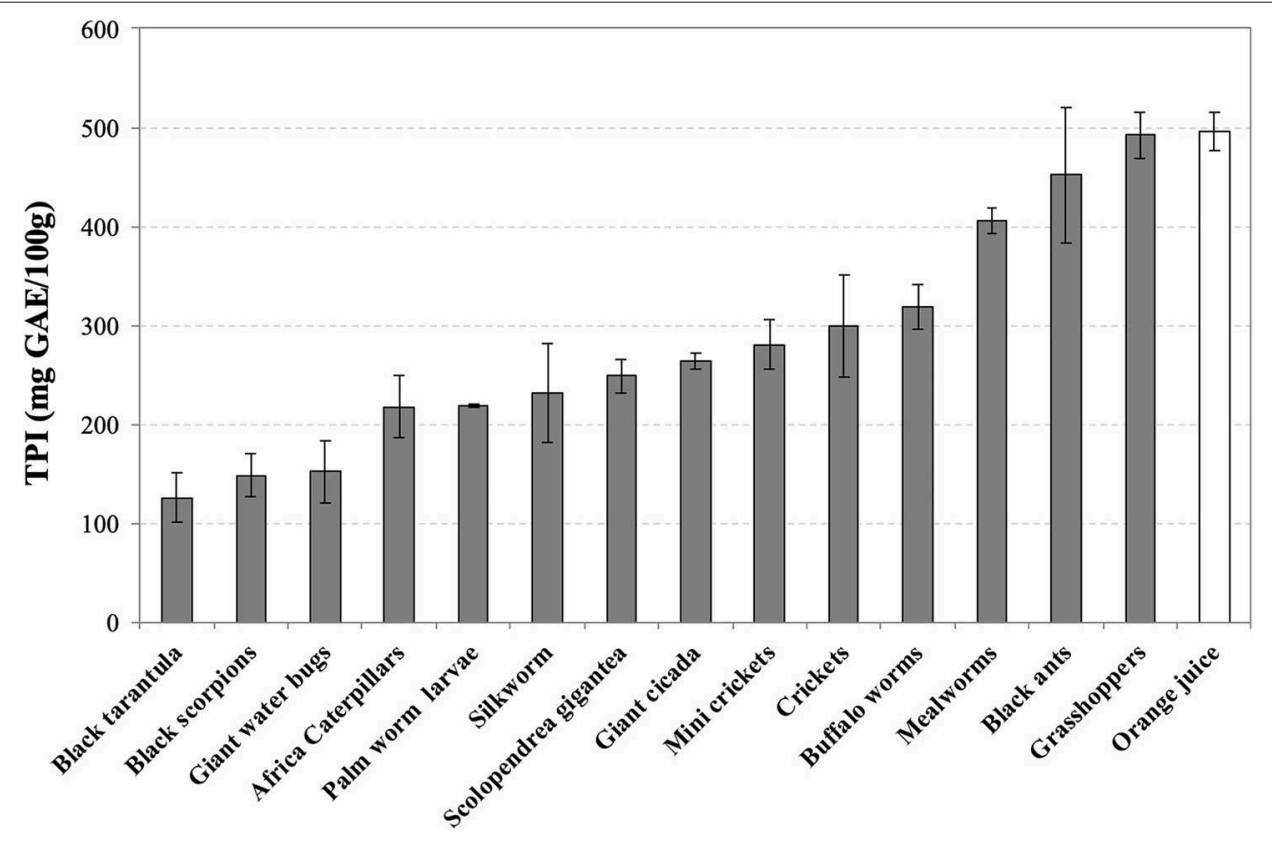

FIGURE 3 | Total Polyphenol Index (TPI) of water-soluble extracts of edible insects, invertebrates, and fresh orange juice. Values are expressed as mgGAE/100 $\mathrm{g}$ of defatted sample or $100 \mathrm{~mL}$ in the case of orange juice and are the mean \pm SD in triplicate. GAE, Gallic acid equivalent.

results in vitro, tailored intervention studies are needed to clarify the antioxidant role of edible insects and invertebrates in human.

The phenolic content of our samples, as determined by TPI, does not show higher values for edible insects compared to fresh orange juice, except for grasshoppers, suggesting that their antioxidant capacity is not only due to this class of compounds. It is possible that, as showed previously by other authors $(12,23,24)$, proteins might contribute to their antioxidant capacity. However, if we consider that FRAP assay do not measure antioxidant contribution from protein groups, 


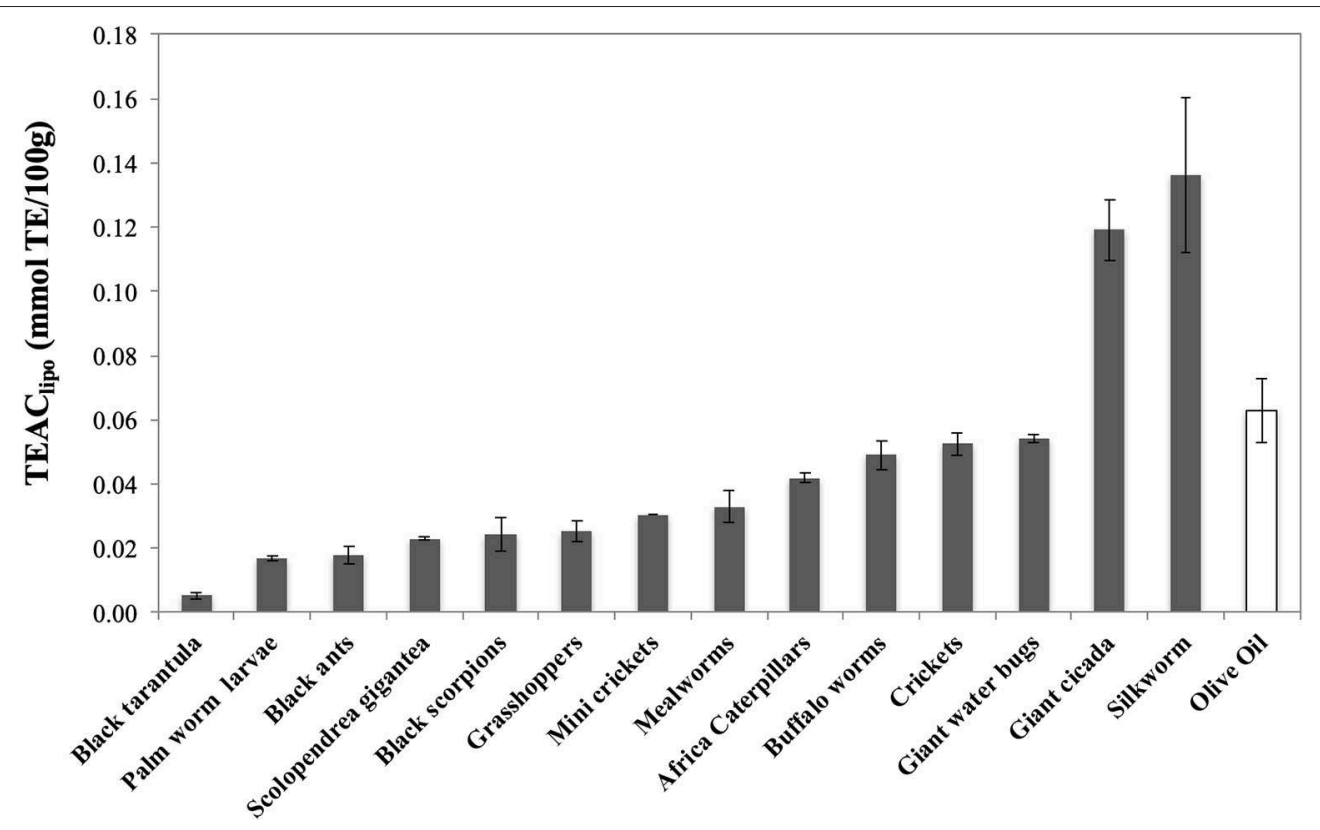

FIGURE 4 | Trolox Equivalent Antioxidant Capacity (TEAC) of lipo-soluble extracts of edible insects, invertebrates, and olive oil. Values are expressed as TEAClip (mmolTE/100 g) and are the mean \pm SD in triplicate. TE, Trolox Equivalents.

we have remarkable higher values compared to orange juice. Moreover, the main antioxidant compounds in orange juice are ascorbic acid and water soluble phenolics, and for olive oil, tocopherols, and amphiphilic phenolics, our results suggest that edible insects are endowed with a peculiar pattern of redox ingredients, ranging from phenolics, proteins as well as unidentified components, able to counteract oxidative stress from water and lipophilic environment.

Our results show that the antioxidant pattern of the edible insects and invertebrates is different according to taxonomy and dietary habits. As regards the water-soluble extracts, we observe that grasshoppers and crickets (orthoptera) and African caterpillars and silkworm (lepidoptera), all characterized by vegetarian dietary habit, are endowed with the highest antioxidant capacity. On the contrary, carnivorous Thai zebra tarantula (arachnids), black scorpions (scorpions), and giant water bugs (rhynchota), are at lowest position of the ranking. However, the scenario change when we analyzed the antioxidant activity of the liposoluble extracts, where silkworm (lepidoptera) is still at the top of the ranking but followed by the carnivorous giant water bugs (rhynchota) and evening cicada (hemiptera), insects that did not display a significant antioxidant activity in the water soluble fraction.

Our results shows that edible insects and invertebrates are an optimal source of bioactive ingredients and of high quality protein, minerals, vitamins, and fatty acids (4), together with a low environmental impact, highlighting their importance as sustainable novel foods under a nutritional, functional, and ecological point of view. In the view of the raising interest of scientific community, media, and consumer for entomophagy, findings of our study are important also under a public health perspective, providing the basis to develop scientificbased campaigns to promote entomophagy and increasing public awareness about the importance of reducing consumption of food at high ecological impact with edible insects, maintaining or even improving nutritional and functional benefits.

In the future we might adapt specific dietary regimen for insects rearing in order to increase antioxidant content and optimizing nutritional intake for a sustainable and functional animal or human consumption, in agreement with the "one health" concept.

\section{CONCLUSION}

Edible insects and invertebrates represent a potential source of unexplored redox ingredients with low ecological impact, with an antioxidant efficiency related to their taxonomy and eating habits. More evidence is needed in order to understand if the practice of eating insects and invertebrates might contribute to modulate oxidative stress in humans and the identification of their bioactive ingredients.

\section{DATA AVAILABILITY}

The datasets generated for this study are available on request to the corresponding author.

\section{AUTHOR CONTRIBUTIONS}

MS designed the experiment. CD conducted the experiments. MS, NB, GS, and CD contributed to data analysis and interpretation and contributed to the manuscript drafting. 


\section{REFERENCES}

1. Bodenheimer FS. Insects as Human Food: A Chapter of the Ecology of Man. Dordrecht: Springer (1951). doi: 10.1007/978-94-017-6159-8

2. DeFoliart GR. Edible insects as mini-livestock. In: Cooper JE, editor. Mini and Microlivestock, Biodiversity and Conservation. (1995). 306-21. Available online at: https://eurekamag.com/research/002/599/002599384.php (accessed July 2, 2019).

3. Costa-Neto EM. Entomotherapy, or the medicinal use of insects. J Ethnobiol. (2005) 25:93-114. doi: 10.2993/0278-0771(2005)25[93:EOTMUO]2.0.CO;2

4. Van Huis A, Van Itterbeek J, Klunder H, Mertens E, Halloran A, Muir G, et al. Edible Insects. Future Prospects for Food and Feed Security. Vol. 171. Rome: Food and Agriculture Organization of the United Nations (2013). 60-4. Available online at: http://www.fao.org/docrep/018/i3253e/i3253e00.htm

5. Pimentel D, Pimentel M. Sustainability of meat-based and plant-based diets and the environment. Am J Clin Nutr. (2003) 78(Suppl.):660S-3S. doi: 10.1093/ajcn/78.3.660S

6. Mason JB, Black R, Booth SL, Brentano A, Broadbent B, Connolly P, et al. Fostering strategies to expand the consumption of edible insects: the value of a tripartite coalition between academia, industry, and government. Curr Dev Nutr. (2018) 2:1-5. doi: 10.1093/cdn/nzy056

7. Gerber PJ, Steinfeld H, Henderson B, Mottet A, Opio C, Dijkman J, et al. Tackling Climate Change Through Livestock. A Global Assessment of Emissions and Mitigation Opportunities. Food and Agriculture Organizations of the United States (2013). Available online at: http://www.fao.org/3/a-i3437e.pdf (accessed July 2, 2019).

8. Chakravorty J, Ghosh S, Meyer-Rochow VB. Practices of entomophagy and entomotherapy by members of the Nyishi and Galo tribes, two ethnic groups of the state of Arunachal Pradesh (North-East India). J Ethnobiol Ethnomed. (2011) 7:5. doi: 10.1186/1746-4269-7-5

9. Sethilkumar N, Barthakur ND, Rao LM. Bioprospecting with reference to medicinal insects and tribes in India: an overview. Indian For. (2008) 132:1575-91. Available online at: http://www.indianforester.co.in/index.php/ indianforester/article/view/870 (accessed July 2, 2019).

10. Stull VJ, Finer E, Bergmans RS, Febvre HP, Longhurst C, Manter DK, et al. Impact of edible cricket consumption on gut microbiota in healthy adults, a double-blind, randomized crossover trial. Sci Rep. (2018) 8:10762. doi: 10.1038/s41598-018-29032-2

11. Tang Y, Debnath T, Choi EJ, Kim YW, Ryu JP, Jang S, et al. Changes in the amino acid profiles and free radical scavenging activities of Tenebrio molitor larvae following enzymatic hydrolysis. PLOS ONE. (2018) 13:e0196218. doi: 10.1371/journal.pone.0196218

12. Zielinska E, Baraniak B, Karaś M. Antioxidant and anti-inflammatory activities of hydrolysates and peptide fractions obtained by enzymatic hydrolysis of selected heat-treated edible insects. Nutrients. (2017) 9:970. doi: 10.3390/nu9090970

13. Dutta P, Dey T, Dihingia A, Manna P, Kalita J. Antioxidant and glucose metabolizing potential of edible insect, Brachytrupes orientalis via modulating Nrf2/AMPK/Glut4 signaling pathway. Biomed Pharmacother. (2017) 95:55663. doi: 10.1016/j.biopha.2017.08.094
14. Re R, Pellegrini N, Proteggente A, Pannala A, Yang M, RiceEvans C. Antioxidant activity applying an improved ABTS radical cation decolorization assay. Free Radic Biol Med. (1999) 26:1231-7. doi: 10.1016/S0891-5849(98)00315-3

15. Benzie IFF, Strain JJ. The ferric reducing ability of plasma (FRAP) as measure of antioxidant power: the FRAP assay. Anal Biochem. (1996) 239:70-6. doi: 10.1006/abio.1996.0292

16. Giacintucci V, Di Mattia C, Sacchetti G, Neri L, Pittia P. Role of olive oil phenolics in physical properties and stability of mayonnaise-like emulsions. Food Chem. (2016) 213:369-77. doi: 10.1016/j.foodchem.2016.06.095

17. Magrone T, Perez de Heredia F, Jirillo E, Morabito G, Marcos A, Serafini M. Functional foods and nutraceuticals as therapeutic tools for the treatment of diet-related diseases. Can J Physiol Pharmacol. (2013) 91:387-96. doi: 10.1139/cjpp-2012-0307

18. Lettieri-Barbato D, Tomei F, Sancini A, Morabito G, Serafini M. Effect of plant foods and beverages on plasma non-enzymatic antioxidant capacity in human subjects: a meta-analysis. Br J Nutr. (2013)109:1544-56. doi: $10.1017 /$ S0007114513000263

19. Serafini M, Miglio C, Peluso I, Petrosino T. Modulation of plasma non-enzimatic antioxidant capacity (NEAC) by plant foods: the role of polyphenols. Curr Top Med Chem. (2011) 11:1821-46. doi: $10.2174 / 156802611796235125$

20. Serafini M, Bugianesi R, Maiani M, Valtuena S, De Santis S, Crozier A. Plasma antioxidants from chocolate. Nature. (2003) 424:1013. doi: 10.1038/4241013a

21. Zamora-Ros R, Serafini M, Estruch R, Lamuela-Raventós RM, MartínezGonzález MA, Salas-Salvadó J, et al. Mediterranean diet and non-enzymatic antioxidant capacity in the PREDIMED study: evidence for a mechanism of antioxidant tuning. Nutr Metabol Cardiovasc Dis. (2013) 23:1167-74. doi: 10.1016/j.numecd.2012.12.008

22. Foroudi S, Potter AS, Stamatikos A, Patil BS, Deyhim F. Drinking orange juice increases total antioxidant status and decreases lipid peroxidation in adults. $J$ Med Food. (2014) 17:612-7. doi: 10.1089/jmf.2013.0034

23. Hall F, Johnson PE, Liceaga A. Effect of enzymatic hydrolysis on bioactive properties and allergenicity of cricket (Gryllodes sigillatus) protein. Food Chem. (2018) 262:39-47. doi: 10.1016/j.foodchem.2018.04.058

24. Nongonierma AB, Fitzgerald RJ. Unlocking the biological potential of proteins from edible insects through enzymatic hydrolysis: a review. Innov Food Sci Emerg Technol. (2017) 43:239-52. doi: 10.1016/j.ifset.2017.08.014

Conflict of Interest Statement: The authors declare that the research was conducted in the absence of any commercial or financial relationships that could be construed as a potential conflict of interest.

Copyright (c) 2019 Di Mattia, Battista, Sacchetti and Serafini. This is an open-access article distributed under the terms of the Creative Commons Attribution License (CC $B Y)$. The use, distribution or reproduction in other forums is permitted, provided the original author(s) and the copyright owner(s) are credited and that the original publication in this journal is cited, in accordance with accepted academic practice. No use, distribution or reproduction is permitted which does not comply with these terms. 